\title{
Laser Capture Microdissection of Hepatic Stages of the Human Parasite Plasmodium falciparum for Molecular Analysis
}

\author{
Jean-Philippe Semblat, Olivier Silvie, Jean-François Franetich, \\ and Dominique Mazier
}

\begin{abstract}
Summary
Despite the sequencing of parasite genomes and development of DNA microarray technology, gene profiling of parasites remains a difficult task. For example, transcriptome analysis cannot currently be applied to the hepatic stages of the malaria parasite Plasmodium falciparum due to difficulties in obtaining sufficient amounts of parasite material that lies among the large excess of host cell RNA. Here, we describe the isolation of $P$. falciparum-infected human hepatocytes by a laser capture microdissection approach. Reverse transcriptase polymerase chain reaction amplification of several $P$. falciparum transcripts demonstrates the high quality of the RNA recovered after microdissection. This approach should enable analysis of $P$. falciparum transcriptome during its hepatic development, a major step toward the identification of new therapeutic and vaccine targets.
\end{abstract}

Key Words: Gene expression; parasite; laser capture microdissection; Plasmodium falciparum.

\section{Introduction}

During the past few years, many parasite genomes have been completely sequenced and others are in progress. This sequence information, in combination with new large-scale genome analysis technologies, provides important tools for molecular studies such as gene expression profiling. However, in the field of parasitology, in the context of a complex background of host nucleic acids, such approaches remain difficult to perform because of the difficulty in isolating the parasite from its host to obtain parasite material pure enough to be 
analyzed. This problem is strengthened when studying an intracellular parasite. For example, Plasmodium falciparum, the malaria parasite that kills more than one million children every year, invades and develops inside the hepatocytes before setting cycles of erythrocytic development associated with the clinical symptoms. Hepatic stages are important targets for vaccine-induced protective immunity and prophylactic treatment (1). However, little is known about the development of the parasites inside the liver. Indeed, molecular analysis, such as a DNA microarray approach, is hampered by the difficulty of isolating parasites from the host cells and by their low density either inside the liver or in hepatocyte cultures. Resulting preparations contain a very low proportion of nuclear material originated from the parasite. Therefore, it is necessary to enrich preparations for infected hepatocytes before molecular analysis.

Laser capture microdissection (LCM) technology appears to be one of the most appropriate approaches to isolate infected cells while saving nuclear material, notably RNA $(\mathbf{2 , 3})$. In parasitology research, few papers have used the LCM approach. One publication does concern the isolation of mouse brain vessels sections to detect gene expression induced by $P$. berghei infection (4); another one demonstrates the feasibility of LCM on tissue sections from $P$. yoelii infected mouse liver for gene expression studies (5). In contrast to rodent malaria, which can be investigated in vitro and in vivo, most of the studies concerning the human plasmodium, $P$. falciparum, hepatic stages need to be performed in cultures. We have recently applied LCM technology to cell cultures in order to isolate $P$. falciparum-infected hepatocytes, the aim being to obtain RNA preparations enriched in parasite material (6).

\section{Materials}

1. HEPES buffer, pH 7.6: $8 \mathrm{~g} / \mathrm{L} \mathrm{NaCl}, 0.2 \mathrm{~g} / \mathrm{L} \mathrm{KCl}, 0.1 \mathrm{~g} / \mathrm{L} \mathrm{Na}_{2} \mathrm{HPO}_{4} \cdot 12 \mathrm{H}_{2} \mathrm{O}$, $2.38 \mathrm{~g} / \mathrm{L}$ HEPES.

2. Collagenase D (Roche, Meylan, France).

3. Percoll.

4. Collagen I (Beckton-Dickinson, Franklin Lakes, NJ).

5. Lab Tek glass slides (Nalge Nunc International, Cergy Pontoise, France).

6. Williams medium E (Life Technology, Cergy Pontoise, France).

7. Fetal calf serum (Life Technology).

8. L-glutamine (Life Technology).

9. Sodium pyruvate (Bio-Whittaker, Miami, FL).

10. Insulin (Sigma, Steinheim, Germany).

11. 5-Fluorocytosin (Roche).

12. Penicillin (Life Technology).

13. Streptomycin (Life Technology).

14. Dexamethasone. 
15. Methanol.

16. Mouse antibodies directed against the $P$. falciparum heat-shock protein 70 (gift from D. Mattei, Institut Pasteur, France).

17. FITC-conjugated goat anti-mouse immunoglobulin (Sigma).

18. RNase inhibitor (Promega, Madison, WI, USA).

19. Ethanol.

20. Xylene.

21. PixCell II LCM system equipped with a fluorescent microscope (Arcturus Engineering, Mountain View, CA).

22. Cap (CapSure $\left.{ }^{\mathrm{TM}} \mathrm{TF}-100\right)$.

23. Sterile $0.5 \mathrm{~mL}$ microcentrifuge tubes.

24. Micro RNA isolation kit (Stratagene, La Jolla, CA).

25. Sensiscript Reverse Transcriptase kit (Qiagen).

26. Fast-start Taq polymerase (Roche).

27. dNTPs.

28. Oligonucleotide primers.

29. Agarose and DNA electroporation equipment.

\section{Methods}

The following methods describe (1) hepatocyte infection, (2) parasite labeling and microdissection, and (3) RNA extraction and reverse transcriptase polymerase chain reaction (RT-PCR).

\subsection{Hepatocyte Infection}

Descriptions of (1) the isolation and culture of human hepatocytes and (2) the infection with $P$. falciparum sporozoites are given below.

\subsubsection{Human Hepatocyte Culture}

1. Primary cultures of human hepatocytes are isolated from liver segments using the two-step enzymatic perfusion technique (7). The hepatic fragments are successively perfused with HEPES buffer to eliminate all blood and with $0.05 \%$ collagenase D in HEPES buffer with $0.75 \mathrm{mg} / \mathrm{mL} \mathrm{CaCl}_{2}$ to dissociate the hepatocytes.

2. Viable cells are isolated by centrifugation at $800 \mathrm{~g}$ on a $36 \%$ Percoll phase. Cells are seeded at a density of $1.4 \times 10^{5}$ per $\mathrm{cm}^{2}$ on a 16-chamber Lab-Tek glass slide (see Note 1) coated with collagen I ( $2 \mathrm{~h}$ with $100 \mu \mathrm{L} / \mathrm{well}$ of a $50 \mu \mathrm{g} / \mathrm{mL}$ solution in $0.02 \mathrm{~N}$ acetic acid) and incubated at $37^{\circ} \mathrm{C}$ in $4 \% \mathrm{CO}_{2}$ atmosphere.

3. Hepatocytes are cultivated in Williams medium $\mathrm{E}$ with $10 \%$ fetal calf serum, $2 \mathrm{mM}$ L-glutamine, $1 \mathrm{~m} M$ sodium pyruvate, $10 \mathrm{mg} / \mathrm{L}$ insulin, $2.5 \mu \mathrm{g} / \mathrm{mL} 5$-fluorocytosin, $200 \mathrm{U} / \mathrm{mL}$ penicillin, and $200 \mu \mathrm{g} / \mathrm{mL}$ streptomycin. After adherence of the cells, culture medium is replaced by fresh medium supplemented with $10^{-7} \mathrm{M}$ dexamethasone. 


\subsubsection{P. falciparum Sporozoite Isolation and Hepatocyte Infection}

1. Anopheles stephensi adult females were infected with the NF 54 strain of P. falciparum, using a membrane-based feeder system (8).

2. After $14-21 \mathrm{~d}$, mosquitoes are killed and their salivary glands are aseptically dissected and disrupted by trituration in a glass tissue grinder. Sporozoites are counted in a KovaSlide ${ }^{\circledR}$ chamber and diluted in culture medium.

3. Hepatocytes are inoculated with $2 \times 10^{5}$ sporozoites per well and incubated at $37^{\circ} \mathrm{C}$ in $4 \% \mathrm{CO}_{2}$ atmosphere for $3 \mathrm{~h}$ and washed three times in complete medium. Finally, fresh complete medium is added and renewed every day (9).

\subsection{Parasite Labeling and Microdissection}

Infected hepatocytes are (1) labeled with an antibody directed against the heat-shock protein 70 (HSP-70) (10), and (2) microdissected by laser capture.

\subsubsection{Parasite Labeling}

1. At appropriate times after inoculation, rinse the cultures three times in $1 X$ PBS. Fix for $5 \mathrm{~min}$ in methanol and wash again three times in 1X PBS.

2. Incubate for $30 \mathrm{~min}$ at $37^{\circ} \mathrm{C}$ with a monoclonal antibody, directed against P. falciparum HSP-70, diluted 1/500 in PBS and containing $400 \mathrm{U} / \mathrm{mL}$ of RNase inhibitor (see Note 2).

3. Wash three times in PBS.

4. Incubate in a FITC-conjugated goat anti-mouse immunoglobulin, diluted 1/100 in PBS with RNase inhibitor, for $20 \mathrm{~min}$ at $37^{\circ} \mathrm{C}$.

5. Wash three times in PBS.

\subsubsection{Laser Capture Microdissection}

To perform an efficient microdissection, it is essential to have the driest sample possible. Cultures are dehydrated through a freshly prepared series of increasing concentrations of ethanol.

1. Incubate first with $70 \%$ ethanol for $30 \mathrm{~s}$, then incubate two times in $95 \%$ ethanol for $1 \mathrm{~min}$ each and two times for $1 \mathrm{~min}$ in 100\% ethanol. Clear slides in xylene by incubating two times $10 \mathrm{~min}$, and finally air-dry in the hood.

2. Without delay, proceed to microdissection using the PixCell II LCM system. Set up the microdissector to $90 \mathrm{~mW}$ of laser power and $15 \mu \mathrm{m}$ diameter laser beam (see Note 3).

3. Put down the cap on the slide that has been inserted in the microdissector. Infected hepatocytes are distinguished from uninfected ones by the fluorescence of the parasites. Ensuring the attachment of the parasite to the membrane of the cap will require several laser pulses (see Note 3 ).

4. When all fluorescent cells have been captured, lift up the cap and control for the absence of the targeted cells. Place a sterile slide on the microscope and put the cap back down on this slide to verify the presence of the fluorescent hepatocytes on the cap. 
5. Lift up the cap again and place into a $0.5-\mathrm{mL}$ Eppendorf microcentrifuge tube for subsequent RNA extraction.

\subsection{RNA Extraction and RT-PCR}

In order to verify the integrity of the RNA after microdissection, we extract the RNA and perform a RT-PCR using primers designed from sequences of genes known to be expressed during the liver stage: $l s a-1$ (11), $l s a-3$ (12), and $h s p-70$ (10). The RNA extraction should be performed directly in the $0.5-\mathrm{mL}$ Eppendorf tube immediately after the microdissection to avoid any RNA degradation.

\subsubsection{RNA Extraction}

The Micro RNA isolation kit used is designed for a small number of cells (small amount of RNA). The protocol is conducted according to manufacturer's recommendations with column centrifugation. A DNase treatment (DNase I at $37^{\circ} \mathrm{C}$ for $15 \mathrm{~min}$ ) is included during the extraction. RNA is eluted with $30 \mu \mathrm{L}$ of preheated $\left(65^{\circ} \mathrm{C}\right)$ elution buffer and stored at $-80^{\circ} \mathrm{C}$. Filter tips are used for the extraction and all Eppendorf tubes are autoclaved prior to use.

\subsubsection{Reverse Transcription}

1. To make the first-strand cDNA, use $12 \mu \mathrm{L}$ of total RNA and mix with $1 \mu M$ oligo $\mathrm{dT}, 0.5 \mathrm{~m} M$ each dNTP, $10 \mathrm{U}$ RNase inhibitor, $1 \mu \mathrm{L}$ of Sensiscript reverse transcriptase in $1 \mathrm{X}$ buffer in $20 \mu \mathrm{L}$ final volume. Perform a negative control reaction with the same volume of RNA using the same reaction mixture lacking the reverse transcriptase enzyme.

2. Incubate the reaction at $37^{\circ} \mathrm{C}$ for $1 \mathrm{~h}$.

3. Inactivate the enzyme by incubating at $93^{\circ} \mathrm{C}$ for $5 \mathrm{~min}$.

\subsubsection{PCR Amplification}

1. Take $2.5 \mu \mathrm{L}$ of first-strand cDNA and mix with $0.4 \mu M$ of each primer, 1 unit of Fast Start Taq polymerase, $200 \mu M$ each of dNTP in a $2 \mathrm{mM} \mathrm{MgCl} 21 \mathrm{X}$ PCR buffer for a total volume of $25 \mu \mathrm{L}$.

2. Amplify using the following PCR conditions: a first denaturation (and activation of the Taq polymerase) step of $4 \mathrm{~min}$ at $95^{\circ} \mathrm{C}$ preceding 40 cycles of amplification composed of a denaturation step at $95^{\circ} \mathrm{C}$ for $45 \mathrm{~s}$, an annealing step at $45^{\circ} \mathrm{C}$ for $45 \mathrm{~s}$, and an extension step at $60^{\circ} \mathrm{C}$ for $1 \mathrm{~min}$. The PCR amplification is terminated by a final extension step at $60^{\circ} \mathrm{C}$ for $10 \mathrm{~min}$.

3. If one round of amplification is not enough to detect the PCR products, amplify $1 \mu \mathrm{L}$ of each PCR product using $0.625 \mathrm{U}$ Taq polymerase in the same mixture and the same amplification conditions as described above, except with an increase in the annealing temperature to $50^{\circ} \mathrm{C}$.

4. Stain the resulting products with ethidium bromide and run on a $1 \%$ agarose gel in $1 \mathrm{X}$ TAE buffer. 


\section{Notes}

1. The diameter of the wells of the 16-chamber Lab-Tek glass slides used is the same as the diameter of the cap, so all the selected cells from one well are microdissected without moving the cap, thus avoiding any contaminations.

2. Hepatocytes are particularly RNase-rich. So it is very important to be careful throughout the experiment to avoid these RNases (similarly for parasite RNase). All steps preceding the microdissection itself should be performed under sterile conditions with sterile reagents. The remaining critical step is the parasite labeling, which is performed at $37^{\circ} \mathrm{C}$. In order to avoid RNA degradation during the incubation at $37^{\circ} \mathrm{C}$, add RNase inhibitor in a concentration of $400 \mathrm{U} / \mathrm{mL}$ to the primary and secondary antibodies. The labeling time can be reduced to $20 \mathrm{~min}$ for the first antibody, and to $15 \mathrm{~min}$ for the second one. Shorter labeling times have been tested, as described in Fend et al. (13), but parasites were not bright enough to be detected during the microdissection. This labeling step should be avoided when transgenic fluorescent sporozoites are used (14).

3. The main difficulty in performing microdissection with hepatocyte cultures is due to their tight attachment to the slide. It is therefore more difficult to capture the cells compared to microdissection of a tissue section, and a high laser power is required for the microdissection. Even so, the bottom membrane of the targeted cell is still attached to the slide and, consequently, the intracellular parasite is not easily captured and sometimes still remains on the slide after the cap is lifted. So, several laser shots (between 3 and 6) are necessary to capture only one parasite. This can explain why several noninfected hepatocytes may be captured along with the infected one. In this type of experiment, targeting an intracellular parasite in hepatocyte cultures, obtaining pure material is nearly impossible. Nevertheless, if the objective is to perform gene expression analysis, even microarray analysis, absolutely pure material is not required and experiments can be successful if the proportion of parasite RNA among the hepatocyte RNA is sufficient.

4. The use of GFP-P. falciparum infected human hepatocytes could be helpful to solve most of the encountered problems.

\section{References}

1 Hoffman, S. L. and Doolan, D. L. (2000) Malaria vaccines-targeting infected hepatocytes. Nat. Med. 6, 1218-1219.

2 Emmert-Buck, M. R., Bonner, R. F., Smith, P. D., Chuaqui, R. F., Zhuang, Z., Goldstein, S. R., et al. (1996) Laser capture microdissection. Science 274, 998-1001.

3 Fend, F., Specht, K., Kremer, M., and Quintanilla-Martinez, L. (2002) Laser capture microdissection in pathology. Methods Enzymol. 356, 196-206.

4 Ball, H. J., McParland, B., Driussi, C., and Hunt, N. H. (2002) Isolating vessels from the mouse brain for gene expression analysis using laser capture microdissection. Brain Res. Protoc. 9, 206-213. 
5 Sacci, J. B., Jr., Aguiar, J. C., Lau, A. O., and Hoffman, S. L. (2002) Laser capture microdissection and molecular analysis of Plasmodium yoelii liver-stage parasites. Mol. Biochem. Parasitol. 119, 285-289.

6 Semblat, J. P., Silvie, O., Franetich, J. F., Hannoun, L., Eling, W., and Mazier, D. (2002) Laser capture microdissection of Plasmodium falciparum liver stages for mRNA analysis. Mol. Biochem. Parasitol. 121, 179-183.

7 Guguen-Guillouzo, C., Campion, J. P., Brissot, P., Glaise, D., Launois, B., Bourel, M., and Guillouzo, A. (1982) High yield preparation of isolated human adult hepatocytes by enzymatic perfusion of the liver. Cell Biol. Int. Rep. 6, 625-628.

8 Ponnudurai, T., Meuwissen, J. H., Leeuwenberg, A. D., Verhave, J. P., and Lensen, A. H. (1982) The production of mature gametocytes of Plasmodium falciparum in continuous cultures of different isolates infective to mosquitoes. Trans. R. Soc. Trop. Med. Hyg. 76, 242-250.

9 Mazier, D., Beaudoin, R. L., Mellouk, S., Druilhe, P., Texier, B., Trosper, J., et al. (1985) Complete development of hepatic stages of Plasmodium falciparum in vitro. Science 227, 440-442.

10 Renia, L., Mattei, D., Goma, J., Pied, S., Dubois, P., Miltgen, F., et al. (1990) A malaria heat-shock-like determinant expressed on the infected hepatocyte surface is the target of antibody-dependent cell-mediated cytotoxic mechanisms by nonparenchymal liver cells. Eur. J. Immunol. 20, 1445-1449.

11 Guerin-Marchand, C., Druilhe, P., Galey, B., Londono, A., Patarapotikul, J., Beaudoin, R. L., et al. (1987) A liver-stage-specific antigen of Plasmodium falciparum characterized by gene cloning. Nature 329, 164-167.

12 Daubersies, P., Thomas, A. W., Millet, P., Brahimi, K., Langermans, J. A., Ollomo, B., et al. (2000) Protection against Plasmodium falciparum malaria in chimpanzees by immunization with the conserved pre-erythrocytic liver-stage antigen 3. Nat. Med. 6, 1258-1263.

13. Fend, F., Emmert-Buck, M. R., Chuaqui, R., Cole, K., Lee, J., Liotta, L. A., and Raffeld, M. (1999) Immuno-LCM: laser capture microdissection of immunostained frozen sections for mRNA analysis. Am. J. Pathol. 154, 61-66.

14. Natarajan, R., Thathy, V., Mota, M. M., Hafalla, J. C. R., Menard, R., and Vernick, K. D. (2001) Fluorescent Plasmodium berghei sporozoites and preerythrocytic stages: a new tool to study mosquito and mammalian host interactions with malaria parasites. Cell Microbiol. 3, 371-379. 